\title{
Empirical Research on the Influence Factors of Fresh Agricultural Products Circulation Ability and Regional Differences
}

\author{
Cheng Yuanyuan ${ }^{1} \&$ Wang Chonghu ${ }^{1}$ \\ ${ }^{1}$ Hunan University of Science and Technology, Xiangtan, Hunan, China \\ Correspondence: Cheng Yuanyuan, Hunan University of Science and Technology, Xiangtan, Hunan, China. \\ E-mail: 1138142900@qq.com
}

Received: May 2, 2017

Accepted: June 1, 2017

Online Published: June 5, 2017

doi:10.5539/ijef.v9n7p147

URL: https://doi.org/10.5539/ijef.v9n7p147

\begin{abstract}
This paper based on the related data to fresh agricultural products circulation ability of 14 cities in Hunan province, applying for the factor analysis model, in order to reveal the important factor and regional differences of fresh agricultural products circulation ability. The results suggest that: from the perspective of the overall of Hunan province, GDP and per GDPPC have the most influences on fresh agricultural products circulation ability; for the different areas of the circulation ability, the effect of the same factors is different; from the time level, the circulation capacity of fresh agricultural products in Hunan province showed a trend of increasing year by year. In terms of space, the different cities have the different the circulation ability of fresh agricultural products.
\end{abstract}

Keywords: fresh agricultural products, circulation ability, the factor analysis model

\section{Introduction}

Based on the division of labor theory and transaction cost theory, which is linked with the circulation capacity of fresh agricultural products, we get that the most important factors influencing the fresh agricultural products circulation ability is the cost of trading. However the transaction cost is determined by the influence factors of fresh agricultural products circulation ability directly or indirectly. In terms of the construction of evaluation index system, the part of the scholars are from the overall level, they study the impact of the economic development, road foundation and political factors on the fresh agricultural products circulation ability, for example: Yang (2011) focuses on the short-term and long-term effects of the policy factors of urbanization on fresh agricultural product circulation ability. From the angle of logistics system, information (the data platform and the public information) and infrastructure, Meng (2013) emphatically analyzes the influence factors of fresh agricultural products circulation ability. The another part of the scholars are from local level, they research the impact of the circulation structure, the changes in consumer buying patterns, the development of the enterprise strategic to the fresh agricultural products circulation ability, such as: Song (2005) discussed the circulation modernization mode, puts forward the circulation structure is a factor deeply affecting the circulation ability of fresh agricultural products in China. From the perspective of SCM theory, Qi (2007) discussed the fruits and vegetables circulation ability, he think too long supply chain will directly affect the circulation ability of fruit and vegetable. Kou (2008) established the evaluation system of the fresh agricultural products circulation ability form the four aspects of consumers, producers, circulation practitioners and the social, every aspect also includes the four specific indicators: the comprehensive efficiency, time efficiency, cost efficiency and safety efficiency. Zhang (2011) from the perspective of current output and cost analyzes the fresh agricultural products circulation ability, and builds the evaluation system of degree of market integration, concentration and other seven indicators.

This paper make comprehensive analysis on the above evaluation index system of fresh agricultural products circulation ability, we argues that the existing index system related to the fresh agricultural products circulation ability have their advantages and disadvantages. For example: The evaluation index system of fresh agricultural products circulation ability which is constructed by Zhang (2011) only includes seven indicators, there are serious information omission. The evaluation index system of fresh agricultural products circulation ability which is built by Kou (2008) includes sixteen indicators, there are a lot of information overlaps and significant multicollinearity. Combined with the existing research, on the basis of data availability, this paper established the evaluation index system of fresh agricultural products circulation ability in Hunan province, it mainly includes 
the following twelve indicators: GDP, GDPPC, arable area, output value of farming, forestry, animal husbandry, and fishery, local financial revenue, per capital rural income, permanent population, urban per capita disposable income, total retail sales of consumer goods, urbanization rate, rural cable penetration, the number of secondary vocational education school.

\section{Research Design}

\subsection{Variable Specification}

Due to the vast area of Hunan province, every city have the different conditions of economic, climate and traffic. Different from the common practice of existing research, there are only one year of data for analysis. This paper uses the statistical data of nearly three years of 14 cities in Hunan province to discussing the circulation ability of fresh agricultural products. Because it can improve the agricultural products circulation ability only by comparing the fresh agricultural products circulation ability of various cities in Hunan province and find out the important factors causing the difference. The index evaluation system of the circulation ability of fresh agricultural products, which is built by this paper, includes twelve indicators. From various angles and comprehensive perspectives, the index evaluation system measures the situation of fresh agricultural products circulation ability. Specific definition of the variables is shown in Table 1.

Table 1. Index evaluation system

\begin{tabular}{|c|c|c|c|}
\hline Variable types & Variable name & Marks & Explanation \\
\hline \multirow{7}{*}{ Circulation subject factors } & arable area & AA & Directly affect the production of fresh agricultural products \\
\hline & $\begin{array}{l}\text { output value of farming, } \\
\text { forestry, animal husbandry, } \\
\text { and fishery }\end{array}$ & OVFFAF & $\begin{array}{l}\text { From the side reflects the economic contribution degree of } \\
\text { fresh agricultural products }\end{array}$ \\
\hline & Per capita rural income & PCRI & Reflects the income of rural residents in a country or a region \\
\hline & urban per capita disposable & UPCD & It is urban income/the number of urban population \\
\hline & $\begin{array}{l}\text { total retail sales of } \\
\text { consumer goods }\end{array}$ & TRSCG & Reflects the consumption of the actual purchasing power \\
\hline & urbanization rate & UR & Urban population /population \\
\hline & $\begin{array}{l}\text { rural cable penetration } \\
\text { the number of secondary } \\
\text { vocational education school }\end{array}$ & $\begin{array}{l}\text { RCP } \\
\text { NSVES }\end{array}$ & $\begin{array}{l}\text { Determines the speed of fresh agricultural products circulation } \\
\text { Determines the technical efficiency of fresh agricultural } \\
\text { products circulation }\end{array}$ \\
\hline \multirow{4}{*}{ Circulation carrier factors } & GDP & GDP & Equal to the sum of the value added of industry \\
\hline & GDPPC & GDPPC & $\begin{array}{l}\text { Closely related to consumption and circulation of fresh } \\
\text { agricultural products }\end{array}$ \\
\hline & local financial revenue & LFR & $\begin{array}{l}\text { Effectively determine the government's ability to provide basic } \\
\text { services for fresh agricultural products circulation size }\end{array}$ \\
\hline & permanent population & $\mathrm{PP}$ & Refers to the total population within a certain time in a region \\
\hline
\end{tabular}

\subsection{Model Construction}

The function of factor analysis is extract the common factors from the variable group. There are six basic steps as follows:

(1) Applying for the sphericity test or KMO test to determine whether a sample is suitable for factor analysis;

(2) Structuring the factor variable, and using the principal component analysis to find the common factor;

(3) Calculating the factor loading matrix;

(4) Rotating the factor loading matrix, and strengthening the explanation of the common factors;

(5) Calculating the factor score, and graphing the map of factor loading.

In general, standardization includes: Min-Max, Z-Score, Standardization of the Log, and so on. This paper selects the Z-Score method, the standardization of data is the standard normal distribution which the mean is equal to zero and the variance is equal to one. The factor model shown as follows.

$$
X=A f+\varepsilon
$$

This paper using Stata software to making the measurement analysis. We research on the samples of 2013, 2014 and 2015 years in turn. 


\section{Results and Discussion}

\subsection{The Quantitative Analysis of the Sample Data of 2013}

Because the selected 12 circulation ability variables may exists a strong relationship, so the first thing is to doing the correlation analysis, the test results are omitted. Through the variance-covariance matrix linked to the whole variables, we can know that, Some of the variables have a strong relationship. Then we use the principal component factor method for factor analysis. The test results are shown in Table 2.

Table 2. Factor analysis results

\begin{tabular}{ccccc}
\hline Factor & Eigenvalue & Difference & Proportion & Cumulative \\
\hline Factor 1 & 6.42322 & 3.21142 & 0.5136 & 0.5236 \\
Factor 2 & 3.57180 & 1.34466 & 0.3310 & 0.8446 \\
Factor 3 & 1.23714 & 0.66337 & 0.0981 & 0.9427 \\
Factor 4 & 0.52377 & 0.03304 & 0.0250 & 0.9677 \\
Factor 5 & 0.21472 & 0.09427 & 0.0164 & 0.9841 \\
Factor 6 & 0.07045 & 0.03192 & 0.0077 & 0.9918 \\
Factor 7 & 0.05253 & 0.02635 & 0.0035 & 0.9952 \\
Factor 8 & 0.02318 & 0.01258 & 0.0024 & 0.9977 \\
Factor 9 & 0.01260 & 0.00215 & 0.0017 & 0.9994 \\
Factor 10 & 0.00365 & 0.00436 & 0.0005 & 0.9998 \\
Factor 11 & 0.00052 & 0.00036 & 0.0002 & 1.0000 \\
Factor 12 & 0.00001 &. & 0.0000 & 1.0000 \\
\hline
\end{tabular}

Note. LR test: independent vs. saturated: $\operatorname{chi} 2(66)=239.23 \quad$ Prob $>$ chi $2=0.0000$.

Factor analysis was performed for 12 circulation ability variables of 14 sample areas to select the top 4 factors whose cumulative contribution of variance accounted to $94.77 \%$, and Chi-Square values were significantly higher. Then, framing the plot of factor loading as follows.

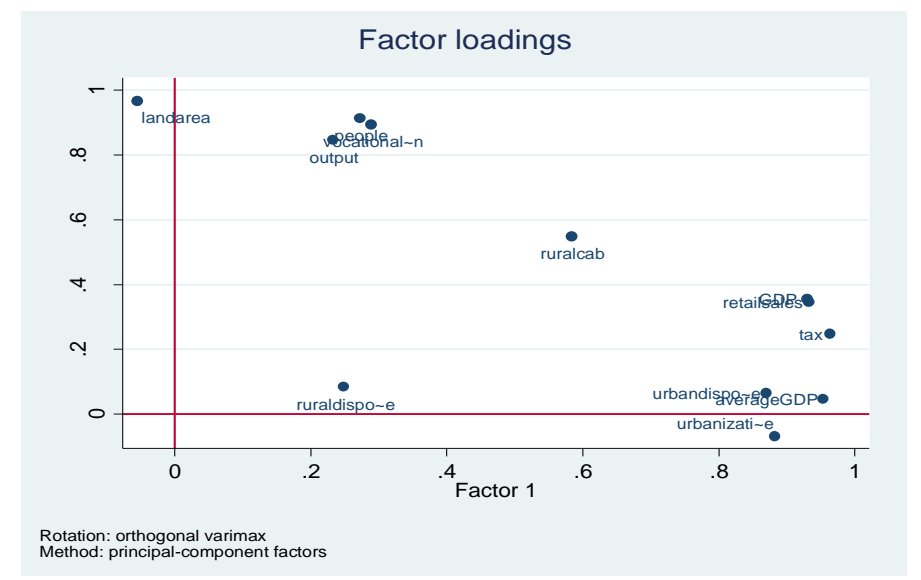

Figure 1. Factor loading figure

According to the factor score matrix, we can calculate factor score function. The expression of factor score function as shown below. It must be pointed out, each of the variables in the expression is not original variables, but standardized variables.

\footnotetext{
Factor $1=0.20595 \mathrm{GDP}-0.03288 \mathrm{PP}+0.20023 \mathrm{GDPPC}+0.23877 \mathrm{LFR}-0.13462 \mathrm{AA}-0.07259 \mathrm{OVFFAF}$

$+0.14506 \mathrm{UR}+0.21789 \mathrm{TRSCG}+0.12922 \mathrm{UPCD}-0.16372 \mathrm{PCRI}+0.02675 \mathrm{NSVES}-0.00823 \mathrm{RCP}$

Factor $2=0.02852 \mathrm{G} D P+0.24990 \mathrm{P} P-0.07297 \mathrm{G} D P P C-0.00235 \mathrm{LFR}+0.29556 \mathrm{~A} A+0.23324 \mathrm{OVFFAF}$

$-0.11410 \mathrm{U} R+0.03229 \mathrm{~T} R S C G-0.06235 \mathrm{UPCD}-0.02405 \mathrm{PCRI}+0.24347 \mathrm{NSVES}+0.08859 \mathrm{RCP}$

Factor $3=-0.16616 \mathrm{GDP}-0.01456 \mathrm{PP}-0.01872 \mathrm{GDPPC}-0.21611 \mathrm{LFR}+0.08093 \mathrm{AA}+0.11787 \mathrm{OVFFAF}$

$+0.16119 \mathrm{U} R-0.20139 \mathrm{TRSCG}+0.15962 \mathrm{UPCD}+0.71578 \mathrm{PCRI}-0.20276 \mathrm{NSVES}+0.25583 \mathrm{RCP}$
} 
Secondly, we draw further on the map of the factor score of 14 cities as follows.

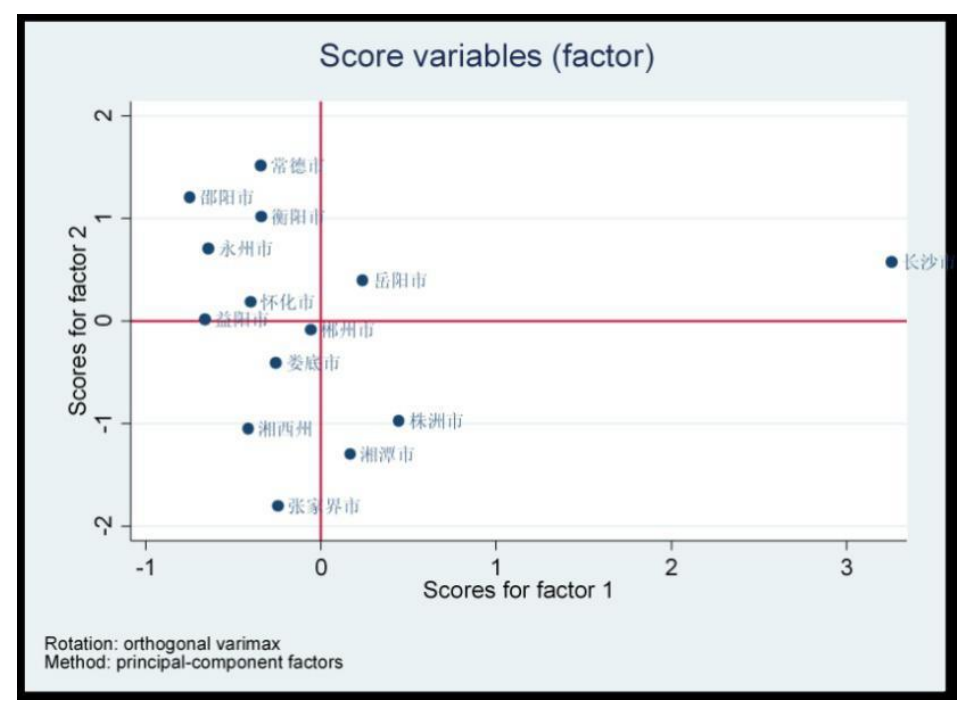

Figure 2. The factor score graph

From the analysis results, 14 cities of Hunan province were assigned to the four quadrants.

The first quadrant including Changsha and eyeing city, the factor score of two cities is best. This shows that the fresh agricultural products circulation ability of Changsha and eyeing city is very strong. The second quadrant mainly include changed, Shao yang, Hengyang, Youhou, Huaihua and Yiyang city. The factor 2 score of six cities is high, but the factor 1 score of six cities is low. This suggests that fresh agricultural products circulation ability of the six cities is general. The third quadrant including Chenzhou, Loudi, Zhangjiajie city and Xiangxi state, the two factors score of four city are relatively low. This indicates that fresh agricultural products circulation ability of the four cities is poor. The fourth quadrant including Zhuzhou and Xiangtan city, The factor 1 score of six cities is high, but the factor 2 score of six cities is low. This shows that the fresh agricultural products circulation ability of Zhuzhou and Xiangtan city is better.

In addition, the KMO test results shows that we adopted factor analysis is appropriate, the factor analysis is effective. We draw the gravel figure of factor analysis on the Figure 3.

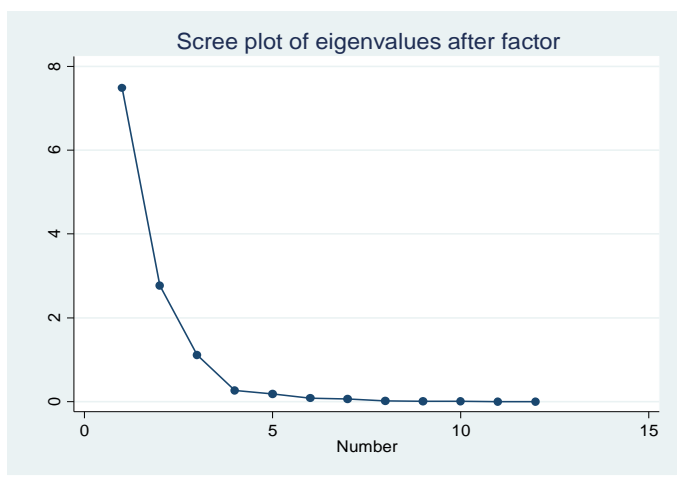

Figure 3. The gravel figure

The test results show that only the characteristic value of the first three factors is greater than 1 . The integrated interpretation ability of model is stronger.

\subsection{The Quantitative Analysis of the Sample Data of 2014}

By correlation test result, there is a strong correlation between the selected multiple variables. On the basis of factor analysis, we make the rotated principal component and factor analysis, the results are shown in the following table. 
Table 3. The rotated principal component and factor

\begin{tabular}{|c|c|c|c|c|c|}
\hline \multicolumn{2}{|c|}{ Factor analysis/correlation } & & Number of obs & 14 & \\
\hline \multicolumn{2}{|c|}{ Method: principal-component factors } & & Retained factors $=$ & 3 & \\
\hline \multicolumn{2}{|c|}{ Rotation: orthogonal varimax (Kaiser off) } & & Number of params = & 32 & \\
\hline Factor & Variance & Difference & Proportion & & Cumulative \\
\hline Factor 1 & 5.87197 & 2.03515 & 0.4893 & & 0.4893 \\
\hline Factor2 & 3.83682 & 2.18050 & 0.3197 & & 0.8091 \\
\hline Factor3 & 1.65632 & 0.00000 & 0.1380 & & 0.9471 \\
\hline
\end{tabular}

Note. LR test: independent vs. saturated: chi2 $(66)=320.03$ Prob $>$ chi2 $=0.0000$.

All of this means that a total of 14 samples are involved in the analysis, there are three factors which are extracted and reserved, and there is no correlation between the extraction factors. Then, we construct the plot of factor loading.

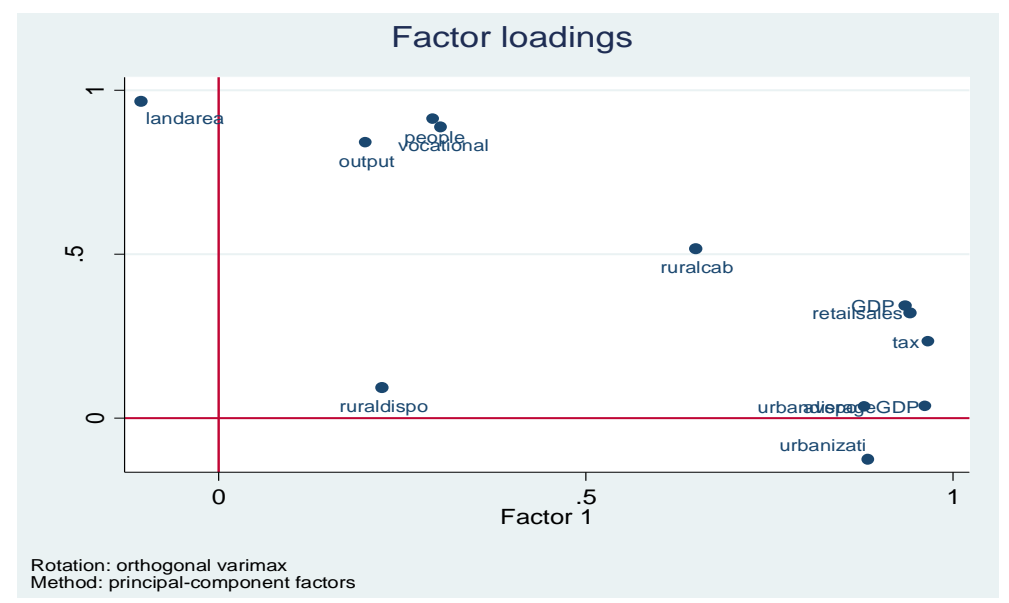

Figure 4. Factor loading figure

The information of PCRI, UPCD, GDPPC and UR variables is mainly explained by Factor 1.The information of AA, OVFFAF, PP and NSVES variables is mainly interpreted by Factor 2.The information of RCP, GDP, TRSCG and LFR is mainly explained by Factor 1 and Factor 2 together. According to the factor score coefficient matrix, the expression of the first three factors considered are as follows. Other conclusions are consistent with the analysis of 2013, so not a tautology.

\subsection{The Quantitative Analysis of the Sample Data of 2015}

According to the results, there are two factors which are extracted and reserved, and the expression of the first two factors calculated are shown in the following.

The factor score schematic diagram is shown in Figure 5.

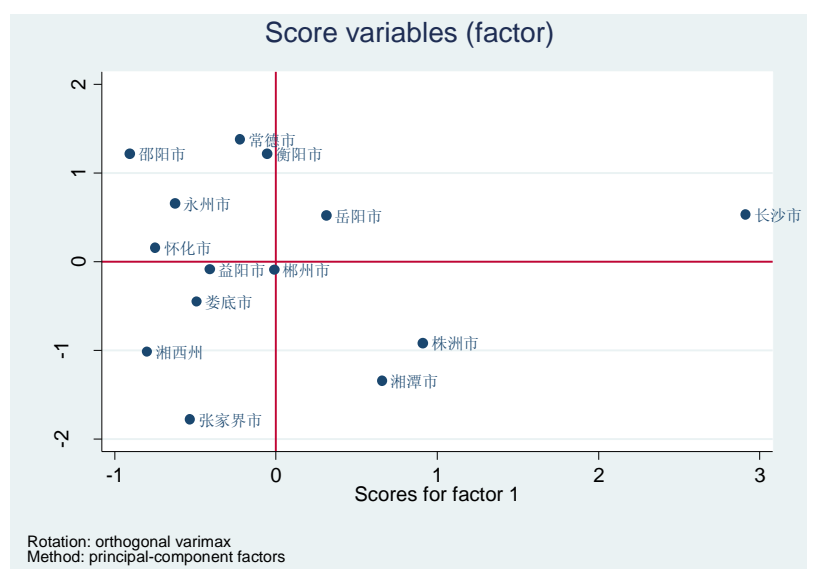

Figure 5. The factor score graph 


\section{Discussion}

According to the empirical analysis of the factors of fresh agricultural products circulation ability in Hunan, drawing the conclusion:

(1) From the perspective of the overall factors, GDP, GDPPC, LFR, UR, TRSCG, UPCD, PCRI and RCP had the significant influence on the dependent variable - fresh agricultural products circulation ability. The effect of other variables is not obvious. The function of circulation carrier factors is stronger than circulation subject factors.

(2) From the view of the local factors, Circulation carrier factors have more influence on fresh agricultural products circulation ability than circulation subject factors in which the circulation ability is best or better. Circulation subject factors have more effect on fresh agricultural products circulation ability than circulation carrier factors in which the circulation ability is general and poor.

(3) From the time level, Fresh agricultural products circulation ability in Hunan province showed a trend of getting better year by year, and the acceleration is bigger and bigger. However, the growth trend is not consistent from region to region.

(4) In terms of space level, the regional differences of fresh agricultural products circulation ability is larger. And the gap is still difficult to eliminate in a short period of time.

\section{Acknowledgments}

This study is supported by the Graduate student research innovation project in Hunan province (number: CX2016B612)

\section{References}

Ahumada, O. et al. (2011). Operational model for planning the harvest and distribution of perishable agricultural products. International Journal of Production Economics, 677-687. https://doi.org/10.1016/j.ijpe.2011.05.015

Ahumada, O. et al. (2012). Tactical Planning of the Production and Distribution of Fresh Agricultural Products under Uncertainty. Agricultural Systems, 17-26. https://doi.org/10.1016/j.agsy.2012.06.002

American Psychological Association. (1972). Ethical standards of psychologists. Washington, DC: American Psychological Association.

Brom, R. (2000). Using farm assarance sehemes to signal food safety to multiple food retailers. The International Food and Agribusiness Management Review, 37-52.

Fujita, M. (2007). Towards the New Economic Geography in the Brain Power Society. Regional Science and Urban Economic, 482-490. https://doi.org/10.1016/j.regsciurbeco.2007.04.004

Golan A. et al. (2004). Food Safety Innovation in the United States:Evidence from the Meat Industry. Economic Research Service, U. S. Department of Agriculture, Agricultural Economic Report, p. 831.

Grievink, J. (2002). Barriers to the advancement of modern food retail formats: Theory and Measurement. Journal of Retailing, 281-295.

Jacques, T. (2004). The impact of transport and transport-cost reductions on food markets in developing countries: Evidence for tempered expections for Burkina Faseo. Agricultural Economics, 219-228.

Kou, R. (2008). Technical efficiency analysis of vegetable wholesale body-based on market survey in Beijing. China Rural Survey, 2-12.

Meng, L. (2013). Problems and countermeasures of modern agricultural products circulation system construction in China. China Circulation Economy, 13-16.

Ouden, D., Dijkhuizen, M. A. A., Huime, R. B. M., \& Zuurbier, P. J. P. (1996). Vertical Cooperation in Agricultural Production-Marketing Chais with Special Reference to Product Differentiation in Pork. Agribusiness,

277-290. https://doi.org/10.1002/(SICI)1520-6297(199605/06)12:3<277::AID-AGR7>3.0.CO;2-Y

Qi, C. J. (2007). Trends and potential of chinese vegetable export to international marke. China Vegetables, 1-4.

Song, Z. (2005). Investigation Report of China logistics Costs Frontier Issues (under). Finance Trade Economics, 58-62.

Yang, J. (2011). The impact of urbanization on agricultural products logistics efficiency. Agricultural Technology Economy, 63-68. 
Zhang, L. (2011). Definition and evaluation index design of agricultural products circulation efficiency. East China Economic Management, 18-21.

\section{Copyrights}

Copyright for this article is retained by the author(s), with first publication rights granted to the journal.

This is an open-access article distributed under the terms and conditions of the Creative Commons Attribution license (http://creativecommons.org/licenses/by/4.0/). 